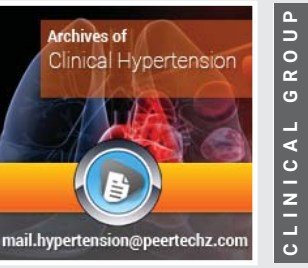

\title{
Blood conservation
}

\section{protocol based on modified ultrafiltration towards bloodless pediatric surgery}

\section{Mohammad Saleh*}

Received: 07 February, 2020

Accepted: 24 February, 2020

Published: 25 February, 2020

*Corresponding author: Mohammad Saleh, Ph.D, Biophysics Lecturer at Department of Physics, Faculty of Science, Aswan University, Sahari city, Airport Way, Aswan, Postal Code: 81528, Egypt, Tel: +2 097 3480446-7 E-mail:mhmd_saleh@hotmail.com

Keywords: Ultrafiltration; Bloodless; Blood conservation; Pediatric; Cardiac surgery; Cardiopulmonay bypass

https://www.peertechz.com

\section{Check for updates}

Ph.D, Department of Physics and Extracorporeal Circulation Team, Aswan University, Aswan, Egypt

\begin{abstract}
Background: Cardiopulmonary Bypass (CPB) application may cause severe hemodilution and an acute systemic inflammatory response syndrome, especially with blood components transfusion. Multi-function circuit of cardioplegia delivery, conventional ultrafiltration, and modified ultrafiltration was advocated to reverse the CPB hemodilution and conserve patient's blood through a blood conservation protocol.
\end{abstract}

Methods: Retrospectively, 600 pediatric were randomly and equally distributed into six studied (S) and control (C) groups. Groups had been classified according to weights as following; $30 \mathrm{~kg} \geq$ groups IS and IC >20 kg $\geq$ groups IIS and IIC $>10 \mathrm{~kg} \geq$ groups IIIS and IIIC $\geq 3 \mathrm{~kg}$, only studied groups were treated with the blood conservation protocol. The fluid management, blood components conservation, and pediatrics clinical outcome characteristics will be investigated in this study.

Results: $100 \%$ achievements for zero fluids balance and bloodless surgery for studied pediatrics of weights $\geq 6 \mathrm{~kg}$ with significant autotransfusion amounts of RBCs, plasma and total protein $(p<0.02)$. Studied pediatrics of weights $<6 \mathrm{~kg}$ received a significantly lesser amount of homologous packed red blood cells, fresh frozen plasma, platelets $(p<0.05)$ and protein product $(p<0.01)$ compared with control pediatrics. Studied groups showed a gradual increase in mean arterial pressure during modified ultrafiltration process, with significant lesser collectively total dopamine dose $(p<0.05$ and $p<0.02$ for weights range of $30-6 \mathrm{~kg}$ and $<6 \mathrm{~kg}$ respectevely). Significant lower blood loss $(p<0.01)$ and shorter intubation duration and ICU stay $(p<0.05$ for group IS and $p<0.01$ for groups IIS and IIIS) observed for the studied groups.

Conclusion: The blood conservation protocol under investigation is a successful method using routine CPB unit components facilitating bloodless surgery for pediatric weights range of $6-30 \mathrm{~kg}$.

\section{Introduction}

Fluid management and blood conservation should be the first priority in perfusion field interests to overcome in pediatric open-heart surgery. Cardiopulmonary Bypass (CPB) may cause severe hemodilution and an acute systemic inflammatory response syndrome; hemodilution can leads to a dilutional coagulopathy with reduced levels of most hemostatic elements causing bleeding disorders and excessive perioperative blood loss. As systemic inflammation response, the development of capillary fluid leakage, causing protein and fluids shift into interstitial space increasing total body water resulted in hypovolemia with the need for blood product transfusion [13] and increasing of the postoperative myocardial dysfunction and respiratory failure [4-6]. In the other side, there were accumulating evidence of the negative impact associated with Red Blood Cells (RBCs) transfusion on morbidity and mortality in the pediatric cardiac population, including infection risk, post-injury multiorgan failure, increased hospital and intensive care length of stay, and the costs [710]. The bloodless surgery is not a new concept in pediatric surgery but in fact, is a preferable choice; it will probably become the rule rather than the exception in the future. More effort has been put into reducing the use of blood components in pediatric cardiac surgical centers, however, homologous blood components transfusion continues to be used frequently $[9,11]$. Despite recent advances in CPB technology worldwide, the majority of neonates and infants in our country still require perioperative transfusion of homologous blood components. This study attempted to reduce the use of homologous blood components by a protocol strategy focused on; 1) Minimization of CPB circuit [1]. 2) Restrict the RBCs transfusion for $<7$ and 
$<8 \mathrm{gm} / \mathrm{dL}$ hemoglobin level during bypass and postoperative respectively. 3) Salvage of blood components from the CPB unit residual autologous whole blood [1], which commonly discarded or only partially salvaged. For that resone the MUF was modified and facilitated by creating Cardioplegia Delivery/ Conventional Ultra-filtration/Modified Ultra-filtration Multifunction Circuit (CD/CUF/MUF MFC) as a basic part of blood conservation strategy towards bloodless pediatric cardiac surgery [12]. The using of such MFC in congenital CPB field, which had been implemented with a great efficacy in perfusion practice of all conducted pediatric cardiac surgeries during 2010 to 2016, offered bloodless cardiac surgery for pediatrics $\geq 6 \mathrm{~kg}$ weights with routine $\mathrm{CPB}$ equipment. The study will be evaluate retrospectively the efficacy of MFC, quantifying its use to get the zero fluids balance, and the ability to minimize the exposure to allogeneic transfusion while maximizing the use of autologous blood components. So the study designed to investigate the impact of blood conservation protocol on fluids management and blood components conservation with the estimation of some clinical outcomes.

\section{Materials and methods}

\section{Ethics and population}

The current study was performed according to the Helsinki Declaration and approved by the research institution of Aswan
University and I followed the rules of Aswan university hospital institutional review board, which considered the informed consent for cardiac surgery for all cases that obtained from the pediatric relatives. 600 pediatric underwent an elective corrective congenital heart surgery for repair a variety of congenital heart defects using CPB procedure from January 2010 to September 2016 at Aswan university hospital cardiac center, Aswan, Egypt. For the purpose of the retrospective study, patients were assigned randomly and equally into studied groups (IS, IIS, and IIIS) and control groups (IC, IIC, and IIIC) and classified on weights base (30kg $\geq$ groups IS and IC $>20 \mathrm{~kg} \geq$ groups IIS and IIC $>10 \mathrm{~kg} \geq$ groups IIIS and IIIC $\geq 3 \mathrm{~kg}$ ). The studied groups were obeyed the blood conservation protocol under discussion and the routine CPB procedures had been conducted to the control groups.

\section{Demographic analysis and CPB data}

The patients' demographics and perioperative characteristics were represented in Table 1 , without statistically discernible differences between all groups. There were no postoperative complications, adverse neurologic events, and all patients survived.

\section{Study meaning and exclusion criteria}

This article is meant to present a blood conservation

Table 1: Summary of patient's demographics and perioperative characteristics.

\begin{tabular}{|c|c|c|c|c|c|c|c|c|}
\hline & Group IS & Group IC & Group IIS & Group IIC & Group IIISA & Group IIICA & Group IIISB & Group IIICB \\
\hline \multicolumn{9}{|c|}{ Demographics } \\
\hline Age (years/months) & $(7 / 6) \pm(1 / 3)$ & $(6 / 10) \pm(1 / 8)$ & $(3 / 8) \pm(1 / 5)$ & $(4 / 3) \pm(0 / 7)$ & $(1 / 0) \pm(0 / 2)$ & $(0 / 9) \pm(0 / 4)$ & $(0 / 3) \pm(0 / 1)$ & $(0 / 2.5) \pm(0 / 1.5)$ \\
\hline Gender (girl/boy) & $61 / 39$ & $63 / 37$ & $56 / 44$ & $54 / 46$ & $39 / 61$ & $42 / 58$ & $62 / 38$ & $64 / 36$ \\
\hline Body weight (kg) & $25.7 \pm 2.66$ & $25.29 \pm 2.77$ & $15 \pm 3.1$ & $14.48 \pm 3$ & $8.18 \pm 1.33$ & $7.5 \pm 1.2$ & $4.39 \pm 0.9$ & $4.22 \pm 0.87$ \\
\hline $\mathrm{BSA}\left(\mathrm{m}^{2}\right)$ & $0.97 \pm 0.091$ & $0.94 \pm 0.093$ & $0.46 \pm 0.09$ & $0.44 \pm 0.092$ & $0.19 \pm 0.029$ & $0.12 \pm 0.019$ & $0.081 \pm 0.016$ & $0.065 \pm 0.013$ \\
\hline Ejection fraction (\%) & $60 \pm 6$ & $63 \pm 8$ & $64 \pm 5$ & $58 \pm 9$ & $76 \pm 8$ & $74 \pm 6$ & $82 \pm 7$ & $77 \pm 4$ \\
\hline \multicolumn{9}{|c|}{ Perioperative characteristics } \\
\hline \multicolumn{9}{|c|}{ Preoperative concentrations of blood cells and proteins: } \\
\hline Hemoglobin (gm/dL) & $10.8 \pm 0.6$ & $11.2 \pm 0.8$ & $11.5 \pm 0.5$ & $10.9 \pm 0.5$ & $10.6 \pm 0.9$ & $11.4 \pm 0.6$ & $10.9 \pm 1$ & $10.1 \pm 0.9$ \\
\hline Plateletscount $\left(\times 10^{9} / \mathrm{L}\right)$ & $310 \pm 50$ & $300 \pm 60$ & $340 \pm 65$ & $311 \pm 30$ & $250 \pm 20$ & $245 \pm 20$ & $235 \pm 50$ & $200 \pm 45$ \\
\hline $\mathrm{TPC}(\mathrm{gm} / \mathrm{dL})$ & $7.1 \pm 1.3$ & $6.4 \pm 0.9$ & $6.5 \pm 1.2$ & $7.2 \pm 0.4$ & $5.9 \pm 1.2$ & $6.5 \pm 0.8$ & $5.1 \pm 0.9$ & $5.9 \pm 1$ \\
\hline \multicolumn{9}{|c|}{ Blood parameters: } \\
\hline ACT & $122 \pm 11$ & $125 \pm 7$ & $128 \pm 13$ & $126 \pm 5$ & $121 \pm 9$ & $124 \pm 12$ & $123 \pm 6$ & $127 \pm 10$ \\
\hline PT - median & $13.5 \pm 0.5$ & $13.2 \pm 0.03$ & $14.2 \pm 0.2$ & $14.1 \pm 0.3$ & $13.3 \pm 0.4$ & $13 \pm 0.6$ & $14.1 \pm 0.7$ & $14.4 \pm 0.1$ \\
\hline \multicolumn{9}{|c|}{ CPB data: } \\
\hline CPB time (min) & $105 \pm 10$ & $95 \pm 17$ & $111 \pm 19$ & $115 \pm 15$ & $120 \pm 18$ & $127 \pm 13$ & $137 \pm 16$ & $130 \pm 25$ \\
\hline Cross-clamp time (min) & $72 \pm 20$ & $65 \pm 25$ & $68 \pm 15$ & $75 \pm 10$ & $80 \pm 30$ & $85 \pm 23$ & $97 \pm 18$ & $90 \pm 22$ \\
\hline Pump time (min) & $130 \pm 11$ & $120 \pm 18$ & $133 \pm 15$ & $135 \pm 21$ & $140 \pm 25$ & $152 \pm 14$ & $162 \pm 19$ & $160 \pm 24$ \\
\hline \multicolumn{9}{|c|}{ Anomaly-correction: } \\
\hline ASD-closure & 6 & 8 & 5 & 2 & 0 & 1 & 2 & 0 \\
\hline VSD-closure & 17 & 15 & 13 & 11 & 30 & 35 & 32 & 40 \\
\hline AVSD-correction & 37 & 33 & 36 & 40 & 25 & 20 & 37 & 29 \\
\hline TOF-correction & 22 & 24 & 25 & 31 & 22 & 29 & 16 & 12 \\
\hline Other & 18 & 20 & 21 & 16 & 23 & 15 & 13 & 19 \\
\hline
\end{tabular}

ACT: Activated Clotting time; ASD: Atrial Septal Defect; AVSD: Atrial Ventricular Septal Defect; BSA: Body Surface Area; CPB: Cardiopulmonary Bypass; PT: Prothrombin Time; TOF: Tetrology of Fallot; TPC: Total Protein Concentration;VSD: Ventricular Septal Defect. 
protocol of fluids and blood transfusion management intraand post-operative based on MFC, with investigating this advocated circuit, its use, complications, benefits, and safety towards bloodless pediatric cardiac surgery. Exclusion criteria; 1) Complicated procedures and unexpected blood loss. 2) Patients who experienced re-on bypass with re-cardiac arrest existence or not. 3) Patients who underwent re-operations. 4) Patients with known clotting disorders or required mechanical support postoperatively. 5) Cyanotic pediatrics because of patient hemodynamic instability.

\section{Anesthesia and anticoagulation}

All patients received the standard general anesthesia management for pediatric cardiac surgery. Anticoagulation was established with an initial bolus of porcine heparin 300 IU/kg "Heparin, Leo Pharmaceutical Products", if needed an additional heparin dose was administrated to maintain Activated Clotting Time (ACT) values higher than 480 seconds, measured using Hemochron "Hemochron Jr ® "ITC, Edison, NJ", Helena Laboratories, Australia". At the end of CPB initial Protamine sulfate dose of $3-3.5 \mathrm{mg} / \mathrm{kg}$ was administered over 3-5 min, if necessary an extra dose was given for more heparin neutralization action and to achieve an ACT values equal or close to the baseline values at the beginning of heart cannulation. All patients received $30 \mathrm{mg} / \mathrm{kg}$ of corticosteroids (methylprednisolone) just before and after CPB, with $100 \mathrm{mg} / \mathrm{kg}$ tranexamic acid "as hemostatic drug" loaded during induction and another $100 \mathrm{mg} / \mathrm{kg}$ added to the pump prime, along with a steroid (dexamethasone) $1-10 \mathrm{mg} / 100 \mathrm{~mL}$ of CPB unit prime.

\section{CPB procedure}

Based on the calculated patient's blood flow, QUADROX-I Pediatric and Neonatal oxygenation systems (Maquet getting group, Sweden Hirrlingen, Germany) with customized arteriovenous loops $1 / 4^{\prime \prime} \times 3 / 8^{\prime \prime}$ and $1 / 4^{\prime \prime} \times 1 / 4^{\prime \prime}$ were utilized for the studied and control groups I, II and III respectively. The CPB circuits were primed with Ringer lactate (Ringer's Solution; Baxter, Utrecht, The Netherlands) solution of $5 \%$ human albumin concentration (Buminate Human Albumin $20 \%$, Adamo healthcare, India), mannitol dose of $0.25 \mathrm{gm} / \mathrm{kg}$ (20\% Mannitol Injectionn USP, B. Braun Medical Inc., USA) and PRBCs was added if needed with a total prime volume detailed in Table 2. CPB was conducting of target nonpulsatile calculated blood flow of $2.4-3.2 \mathrm{~L} / \mathrm{min} / \mathrm{m} 2$ utilizing a roller pump (Sorin Stockert S3) keeping mixed venous oxygen saturation values above $60 \%$ and the range of $30-60 \mathrm{mmHg}$ mean arterial pressure with mild hypothermia of $28-32{ }^{\circ} \mathrm{C}$. Arterial blood gas (alpha-stat strategy), venous saturation, electrolyte, glucose, lactate, hemoglobin $(\mathrm{Hb})$ levels and ACT were continuously monitored. Myocardial preservation was achieved with intermittent cold blood cardioplegia composed of crystalloid cardioplegic solution mixed with oxygenated blood at the ratio of $1: 4$, with an initial dose of $30 \mathrm{~mL} / \mathrm{kg}$ followed by half initial dose every 20-30 min. All the delivered cardioplegia fluids, surgical field blood, and all crystalloids have been added to keep the dynamic blood level during CPB above the reservoir recommended level, were aggressively filtered (CUF) in order to keep zero fluid balance as far as possible until CPB conclusion. MUF process was done after CPB termination using MFC composed of cardioplegia heat exchanger "PLEGIOX" and polyethersulfone ultrafilter "BC20 PLUS" (Maquet getting group, Sweden Hirrlingen, Germany) (Figure 1).

\section{The strategy of minimizing blood components transfu- sion}

Protocol strategy was formulated then agreed by all operating teams, andit contains two branches; First: achieve hemodilution reduction and blood component conservation by the collaborating of anesthesia, perfusion, and intensive care unit (ICU) teams as follows. At the anesthesia team side; the staff made every effort to minimize the amount of intravenous crystalloid infusion throughout the operation especially from induction up to the beginning of $\mathrm{CPB}$ that minimizing powerfully the hemodilution, which was a great help to get the expected calculated hemoglobin level during CPB. At perfusion team side; achieving low prime volume, by miniaturize $\mathrm{CPB}$ unit, reducing the length of roller pump head tubes connected between oxygenator and reservoir, also reduce the length of the surgical table side part of arterial and venous lines and constructe the arterial bifurcation closed enough to the MFC blood head (Figure 1). Low prime hollow-fiber membrane oxygenators and optimally designed reservoir for minimal recommended level were used. CPB unit was positioned close enough to the surgical table while avoiding crowdedness around the surgeon and assistant (Figure 2). The prime RBCs transfusion was restricted to reach $7 \mathrm{gm} / \mathrm{dL}$ during bypass. In order to allow perfusionist having a quick calculation for the needed PRBCs quantity in prime, we can use the following formula;

[(expected body volume + total prime volume/100 $) \times$ 21-(patient Hct $\times$ expected body volume)]/70

Extended hemofiltration was conducted for hemic prime circuits and go-down with the dynamic level to meet the recommended reservoir level (Figure 3). As highlighting the step of adjusting dynamic level to the recommended reservoir level, the individual patient dynamic level can be determined easily by increasing the prime flow to the calculated full flow and pressurize the circuit to the range around $250 \mathrm{mmHg}$. Additional crystalloids or colloids administration during CPB was at the discretion of the perfusionist, based upon the working volumes. RBCs transfusion aggressively restricted, unless it was needed during bypass, of low hematocrit (Hct) level and/or low venous saturation, and after the consultation with the surgeon and anesthetist.

The rewarming process should be shifted to the final stage of the CPB procedure and to be ended by the end of the $\mathrm{CPB}$ procedure, then immediately start MUF restoring the normal patient blood component parameters. During MUF, the calculation of the target plasma water filtration volume in order to remove the added crystalloids and bring the patient circulation to zero crystalloids balance, we can be using the following formula; 
Table 2: Investigated parameters results.

\begin{tabular}{|c|c|c|c|c|c|c|c|c|}
\hline & Group IS & Group IC & Group IIS & Group IIC & Group IIISA & Group IIICA & Group IIISB & Group IIIC \\
\hline \multicolumn{9}{|c|}{ CPB prime volume and components } \\
\hline Prime volume $(\mathrm{mL})$ & $500 \pm 50^{\S}$ & $700 \pm 75$ & $500 \pm 50^{\S}$ & $650 \pm 75$ & $400 \pm 50 \S$ & $600 \pm 75$ & $400 \pm 50 \S$ & $550 \pm 75$ \\
\hline \multicolumn{9}{|c|}{ Prime components volumes $(\mathrm{mL})$ : } \\
\hline PRBCs & - & $325 \pm 50$ & - & $300 \pm 50$ & - & $275 \pm 50$ & $75 \pm 25^{\S}$ & $235 \pm 50$ \\
\hline Protein product $20 \%$ & $125 \pm 20^{+}$ & $100 \pm 15$ & $125 \pm 20$ & $125 \pm 25$ & $125 \pm 20^{+}$ & $100 \pm 15$ & $75 \pm 25$ & $75 \pm 15$ \\
\hline Mannitol $20 \%$ & $30 \pm 5$ & $35 \pm 3$ & $20 \pm 4$ & $18 \pm 6$ & $10 \pm 3$ & $12 \pm 4$ & $5 \pm 2$ & $5 \pm 2.5$ \\
\hline \multicolumn{9}{|c|}{ Additional solutions and blood components } \\
\hline \multicolumn{9}{|c|}{ Solutions: } \\
\hline Ringer lactate volumes $(\mathrm{mL})$ & $250 \pm 75^{\S}$ & $100 \pm 50$ & $225 \pm 75^{+}$ & $100 \pm 50$ & $175 \pm 50^{+}$ & $50 \pm 25$ & $125 \pm 50^{*}$ & $50 \pm 25$ \\
\hline \multicolumn{9}{|c|}{ Homologous blood components volumes $(\mathrm{mL})$ : } \\
\hline PRBCs (OR / ICU) & - & $150 / 75$ & - & $125 / 150$ & - & $125 / 50$ & $50 / 25$ & $100 / 50$ \\
\hline Total PRBCs & - & $225 \pm 50$ & - & $275 \pm 50$ & - & $175 \pm 25$ & $75 \pm 25^{\star}$ & $150 \pm 50$ \\
\hline $\mathrm{FFP}(\mathrm{OR} / \mathrm{ICU})$ & - & $25 / 125$ & - & $50 / 125$ & - & $50 / 100$ & $50 / 75$ & $75 / 125$ \\
\hline Total FFP & - & $150 \pm 25$ & - & $175 \pm 50$ & - & $150 \pm 50$ & $100 \pm 75^{*}$ & $200 \pm 50$ \\
\hline Protein product $20 \%$ & - & $25 \pm 10$ & - & $20 \pm 15$ & - & $20 \pm 10$ & $15 \pm 5^{\S}$ & $25 \pm 5$ \\
\hline Platelets (OR / ICU) & - & $75 / 45$ & - & $60 / 35$ & - & $70 / 50$ & $40 / 60$ & $40 / 110$ \\
\hline Total platelets & - & $125 \pm 50$ & - & $100 \pm 25$ & - & $125 \pm 25$ & $100 \pm 50^{*}$ & $175 \pm 25$ \\
\hline \multicolumn{9}{|c|}{ Calculated autologous blood components autotransfused: } \\
\hline Approximate PRBCs volume $(\mathrm{mL})$ & $117 \pm 25^{+}$ & $50 \pm 10$ & $130 \pm 35^{+}$ & $50 \pm 20$ & $100 \pm 25^{+}$ & $45 \pm 15$ & $25 \pm 10$ & $20 \pm 5$ \\
\hline Plasma volume (mL) & $255 \pm 50^{+}$ & $150 \pm 25$ & $250 \pm 25^{+}$ & $125 \pm 50$ & $150 \pm 50^{+}$ & $50 \pm 30$ & $50 \pm 30$ & $30 \pm 20$ \\
\hline $\operatorname{TPC}(\mathrm{g} / \mathrm{dl})$ & $1.3 \pm 0.3^{+}$ & $0.34 \pm 0.1$ & $2.15 \pm 0.5^{+}$ & $0.43 \pm 0.15$ & $2.1 \pm 0.5^{\dagger}$ & $0.26 \pm 0.1$ & $1 \pm 0.2$ & $0.85 \pm 0.3$ \\
\hline \multicolumn{9}{|c|}{ Clinical outcome characteristics } \\
\hline \multicolumn{9}{|c|}{ Inotropes in the first day ICU: } \\
\hline Dopamine dose $(\mu \mathrm{g} / \mathrm{kg} / \mathrm{min})$ & $3.1 \pm 0.3^{*}$ & $4 \pm 0.6$ & $2.6 \pm 1^{*}$ & $4.8 \pm 1.6$ & $2.8 \pm 1.2^{*}$ & $5.3 \pm 1.9$ & $3.4 \pm 1.7^{+}$ & $5.9 \pm 1.2$ \\
\hline Adrenaline dose $(\mu \mathrm{g} / \mathrm{kg} / \mathrm{min})$ & $0.05 \pm 0.01$ & $0.07 \pm 0.02$ & $0.04 \pm 0.015$ & $0.06 \pm 0.025$ & $0.03 \pm 0.01$ & $0.05 \pm 0.03$ & $0.06 \pm 0.02$ & $0.08 \pm 0.03$ \\
\hline \multicolumn{9}{|c|}{ Blood loss (mL): } \\
\hline Intra-operative / The first day ICU & $455 / 495$ & $595 / 675$ & $325 / 360$ & $425 / 485$ & $95 / 105$ & $145 / 175$ & $60 / 70$ & $75 / 85$ \\
\hline Total blood loss & $950 \pm 250^{\S}$ & $1270 \pm 215$ & $685 \pm 100^{\S}$ & $910 \pm 125$ & $200 \pm 70^{\S}$ & $320 \pm 50$ & $130 \pm 50$ & $160 \pm 30$ \\
\hline \multicolumn{9}{|c|}{ Durations: } \\
\hline Intubation duration (hours) & $19 \pm 1.5^{\star}$ & $23 \pm 3$ & $25 \pm 4 \S$ & $31 \pm 3$ & $27 \pm 7 \S$ & $38 \pm 5.5$ & $24 \pm 8 \S$ & $41 \pm 10$ \\
\hline ICU time (hours) & $24 \pm 3^{*}$ & $30 \pm 5$ & $33 \pm 3 \S$ & $39 \pm 4$ & $45 \pm 1.5^{\S}$ & $49 \pm 2$ & $61 \pm 8^{\S}$ & $74 \pm 6$ \\
\hline Hospital stay (days) & $4.5 \pm 0.5$ & $5 \pm 1$ & $6 \pm 1$ & $5 \pm 0.5$ & $4 \pm 1.5$ & $5 \pm 2$ & $5.5 \pm 2$ & $7 s \pm 3$ \\
\hline
\end{tabular}

CPB: Cardiopulmonary Bypass; ICU: Intensive Care Unit; OR: Operating Room; TPC: Total Protein Concentration; PRBCs: Packed Red Blood Cells; FFP: Fresh Frozen Plasma; as compared to control groups: ${ }^{*} P<0.05,{ }^{+} P<0.02$ and $\$ P<0.01$.

[(expected body volume/(prime volume + expected body volume $)) \times$ volume of crystalloids part of prime]/[100-((volume of crystalloids part of prime/prime volume $) \times 100$ )]

At ICU team side; the RBCs transfusion restricted to keep $8 \mathrm{gm} / \mathrm{dL}$ level, platelets requirements for counts $<100-150$ $\times 109 / \mathrm{L}$ and Fresh Frozen Plasma (FFP) transfusion according to patient's laboratory tests and clinical status.

Second: modifying the routinely used perfusion equipment "Cardioplegia Delivery System (CDS) and hemoconcentrator" creating the MFC; hemoconcentrator inlet and outlet are connected to the outlet of MFC blood head and the reservoir respectively for the purpose of CUF (Figure 4). During cardioplegia delivery the hemoconcentrator was closed allowing all blood output of cardioplegia blood head to inter the cardioplegia heat exchanger (Figure 5). Shortly, before the end of bypass the hemoconcentrator outlet is switched to the inlet of the cardioplegia heat exchanger and be disconnected from hemoconcentrator inlet by placing a clamp and start washing the CDS contents through its recirculation line slowly into the reservoir using the cardioplegia blood head, so it will be ready for MUF process. At the conclusion of the CPB and with the patients hemodynamics stability, arteriovenous MUF was performed for $20 \mathrm{~min}$ (instead of $10 \mathrm{~min}$ or less of routine MUF time of control groups) using MFC as following; the cardioplegia delivery line should be connected to one of the right atrium cannulae using the proper perfusion adaptor, once the target blood flow "7-10\% of the calculated patient blood full flow" was reached, the filtrate line will be opened and filtration started with 150 and $200 \mathrm{mmHg}$ hemoconcentrator Transmembrane Pressure (TMP) for groups IS, IIS and IIIS 
respectively, by partially closing the cardioplegia delivery line when needed (indicated by "A" in Figure 6). The proper central venous pressure was chosen by the surgeon and anesthetist according to the patient hemodynamics status, and being controlled accurately by replacing the filtered plasma water as it is removed with an equivalent amount of CPB circuit residual blood "every $2 \mathrm{~min}$ for the purpose of pressure measurements recording" through the arterial line regulated by the main arterial pump. When the residual blood was finished in the replacing process, Ringer lactate solution is added to chase the contents of main head tubes, oxygenator, and arterial line until the arterial bifurcation as we can. In the last $4 \mathrm{~min}$, the hemoconcentrator TMP pressures were increased to 200 and $300 \mathrm{mmHg}$ for groups IS, IIS and IIIS respectively in order to chase the maximum quantity of MFC volume back to the patient circulation. After MUF, heparin was reversed by the adequate Protamine sulfate doses. As one of the MFC benefits is

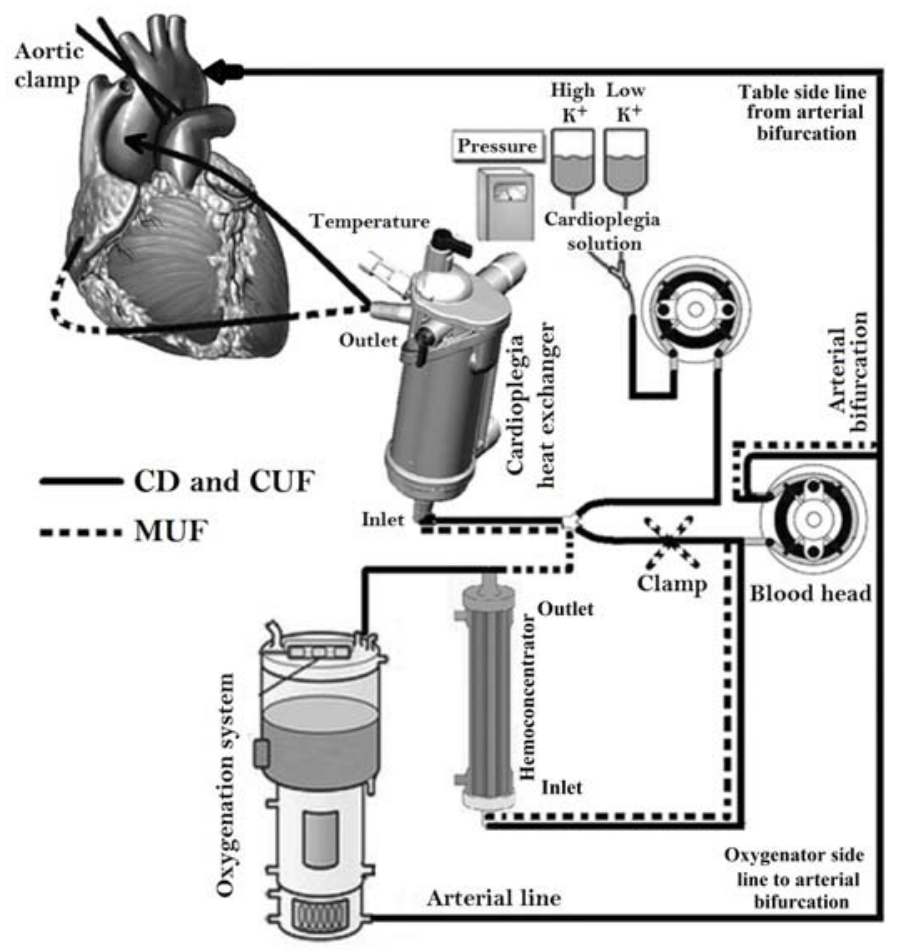

Figure 1: Schematic diagram of Cardioplegiadelivery (CD), Conventional Ultrafiltration (CUF) and Modified Ultrafiltration (MUF) processes.

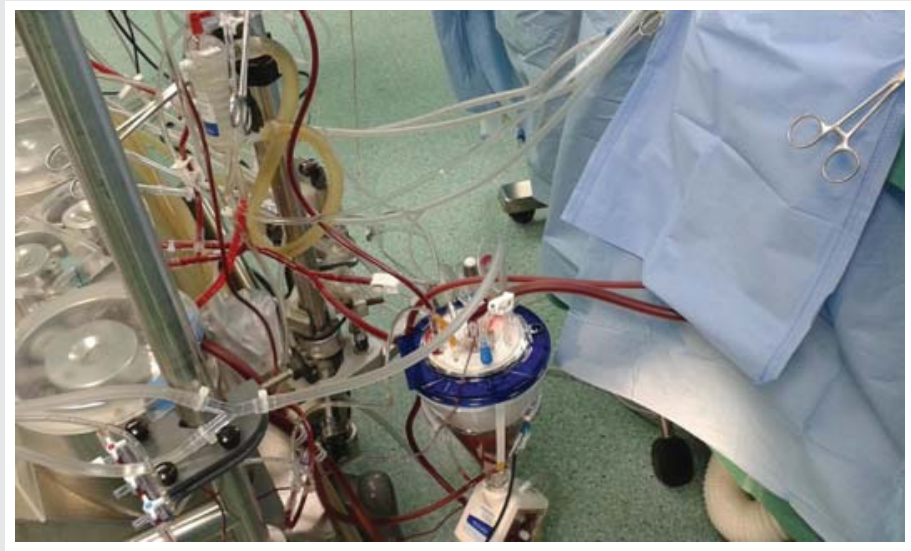

Figure 2: The position of miniaturized CPB unit.

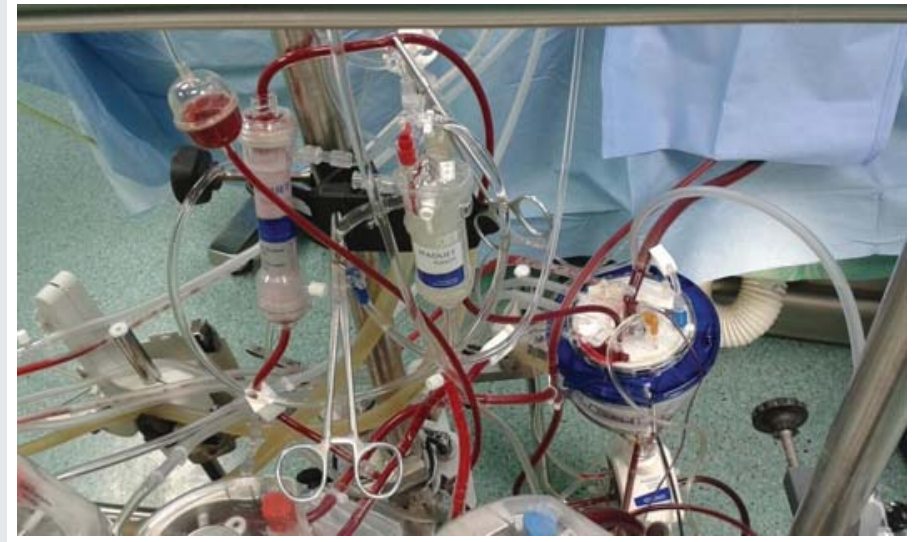

Figure 3: Extended hemofiltration process for studied patient's weights $\leq 6 \mathrm{~kg}$.

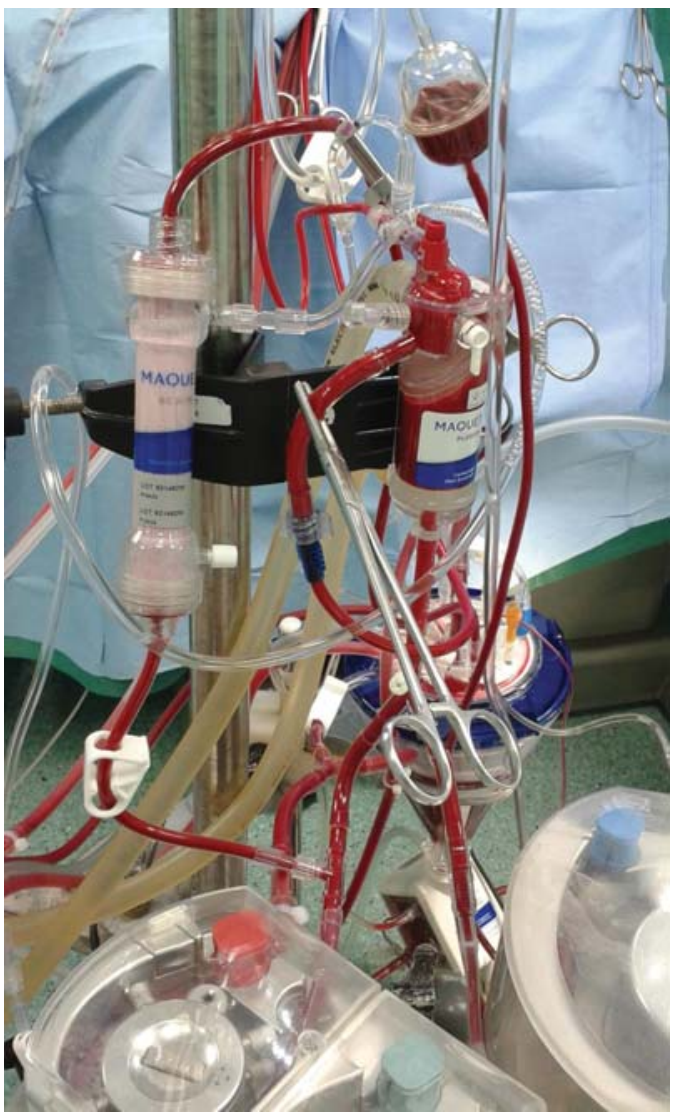

Figure 4: Conventional ultrafiltration process during CPB.

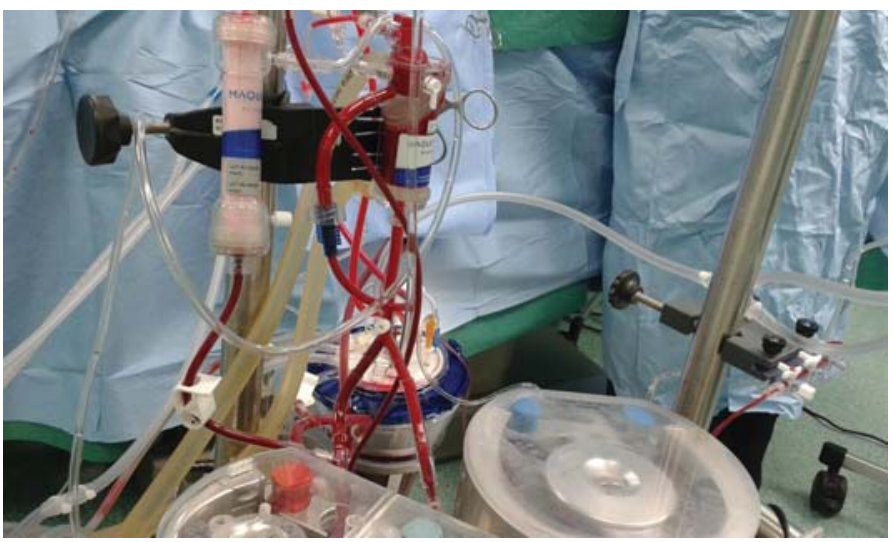

Figure 5: Cardioplegia delivery process

Citation: Saleh M (2020) Blood conservation protocol based on modified ultrafiltration towards bloodless pediatric surgery. Arch Clin Hypertens 6(1): 001-012. DOI: https://dx.doi.org/10.17352/ach.000023 


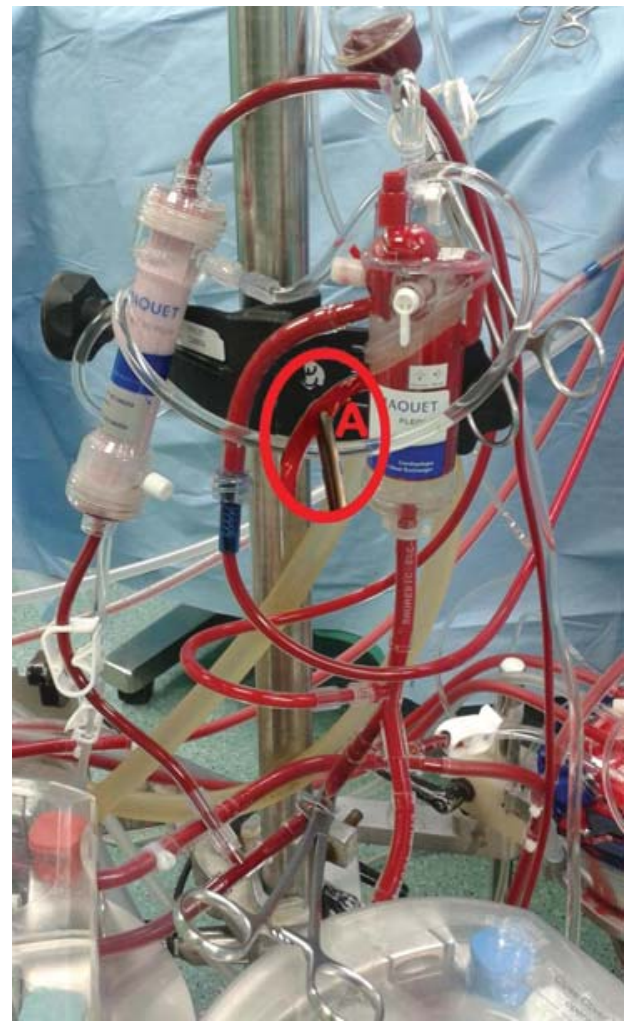

Figure 6: Modified ultrafiltration process.

that, it remains as it is connected without changing the status of any of its components, neither during nor after MUF. Such safe and easy go back to bypass for the purpose of emergencies and deliver cardioplegia through CDS if needed.

\section{Investigated parameters}

Fluid management: Measuring CPB unit and MFC volumes, plasma water filtration rate per 2min during MUF, with performance and timing of zero crystalloids and colloids balance achievement. Blood components conservation: Calculating the homologous blood components transfusion since the time of operating room arrival until the end of first day ICU including the blood products added to the prime. Measuring Hb level, total plasma protein concentration and platelets count values, so the autotransfused blood components amounts using MFC can be calculated. Clinical outcome characteristics: Investigate the conservation protocol impact on systolic pressure during MUF, inotropes doses, lactate level during operation, perioperative blood loss; the intraoperative blood loss was represented as the sum of blood calculated from swabs, discarded suction volumes and the chest drains' output, and postoperative blood loss was represented as the total volume of chest tubes during the first day ICU stay, and finally postoperative durations of intubation, ICU and hospital stay.

\section{Data statistical analysis}

The studied population continuous data are presented as the mean \pm standard deviation of the mean and two tailed Student's t-Test to examine significant differences in measured parameters and collected data, using statistical package IBM SPSS.

\section{Results}

Results showed successful implementation of blood conservation protocol based on MFC. There was an achievement of zero crystalloids balance for all studied patients and zero colloids balance for most of them, decreasing the blood components transfusion and improve hemodynamic, coagulation and other organs functions resulted in postoperative morbidity reduction. Fluid management: Because 44 patients of group IIIS with weights range of $10-6 \mathrm{~kg}$ experienced nonhemic prime, so in the purpose of the further data analysis, each of IIIS and IIIC groups was divided based on weights into two goups as following; $10 \mathrm{~kg} \geq$ groups IIISA and IIICA $\geq 6 \mathrm{~kg}>$ groups IIISB and IIICB $\geq 3 \mathrm{~kg}$. As represented in Table 2 , groups IS, IIS and IIISA had significantly lesser non-hemic priming volumes compared with their control groups, and groups IS and IIISA had significantly more prime protein product compared with their control groups. Studied groups received significant higher additional ringer lactate compared with control groups. Figure 7, represents how the MFC volume (210mL; 100mL tubes $+110 \mathrm{~mL}$ equipment) was a big measurable part of $\mathrm{CPB}$ unit volume for groups IS and IIS and much bigger measurable part of $\mathrm{CPB}$ unit and patients body volumes for groups IIISA and IIISB, the significant increase in plasma water filtration rate for the last 4 min compared with the first 16 min of MUF time $(p<0.01)$. Figure 7 also showed the $100 \%$ of zero crystalloids and colloids balances achievements for groups IS, IIS and IIISA, 100\% and $66 \%$ were the percentages of zero balances achievements for group IIISB of crystalloids and colloids respectively. There was a demonstration for the measured time of $100 \%$ zero crystalloids balances achievements $(\leq 20 \mathrm{~min})$ for all groups, also the measured and calculated time of $100 \%$ zero colloids balances achievements for groups IS, IIS, IIISA and group IIISB respectively ( $\leq 20 \mathrm{~min}$ and $26 \mathrm{~min}$ respectively). Blood components conservation: As represented in table 2., group IIISB had significantly lesser hemic prime volume and RBCs quantity as a prime component with significant lower additional homologous blood components quantities in OR and the first day ICU compared with group IIICB. $\mathrm{Hb}$ and total protein levels measurements were significantly decreased during

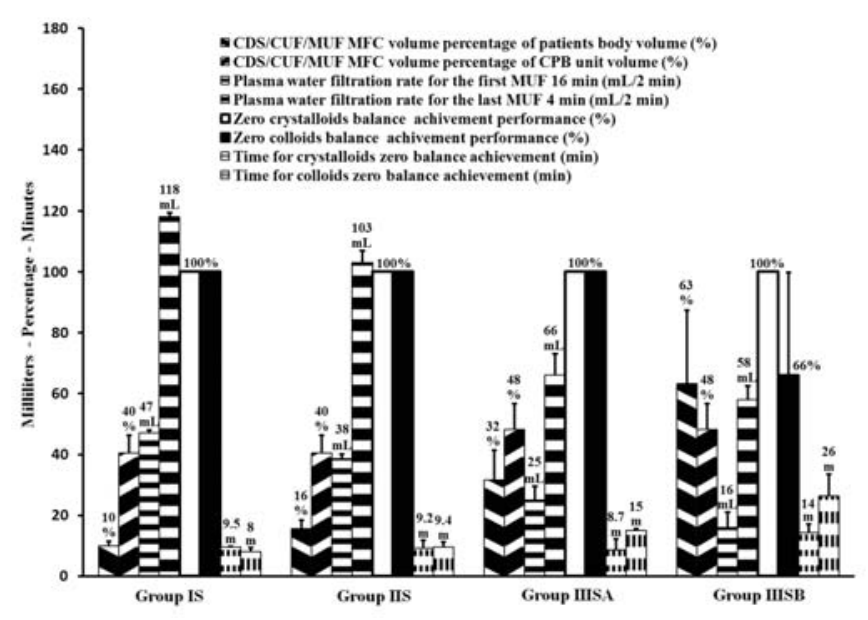

Figure 7: MFC fluid managements. MUF: Modified ultrafiltation; MFC:Cardioplegia Delivery, Conventional Ultra-filtration and Modified Ultra-filtration Multi-function Circuit. 
and pre-bypass $(p<0.01)$ for studied and their control groups respectively compared with their preoperative measurements, with insignificant lower values for groups IS, IIS and IIISA post-MUF compared with their preoperative values (Figure 8 and 9). Platelets count values showed a significant decrease post CPB for all groups ( $p<0.01$ for studied groups and groups IC, IIC and IIICB, and $p<0.02$ for group IIICA), but at 24 hours postoperative groups IS, IIS and IIISA recover to insignificant lower than the pre-bypass values, where IIISB and control groups were not (Figure 10). Consequently, the calculated amounts of RBCs, plasma and total protein autotransfusion for groups IS, IIS and IIISA showed significant high values compared with their control groups, in time were insignificant for group IIISB compared with group IIICB (Table 2). Clinical outcome characteristics: Figure 11, showed gradual increase in systolic pressure during MUF process, specially the significant increase at the start of the last $4 \mathrm{~min}$ of MUF time and at the end of MUF before the chase of MFC contents compared with values at the start of MUF and at the end of first 2min filtration before compensation, respectively ( $p<0.01$ for groups IS and IIS, $p<0.05$ for groups IIISA and IIISB). As represented in Table 2 the types of inotropes used were dopamine and adrenaline; with no significant differences between all groups intraoperative, but postoperatively at the first day ICU the studied groups received a collectively significant lesser total dose of dopamine compared to control groups. However, there was no significant difference between the studied and control groups in the total dose of required adrenaline in this period. Lactate level values were $(1.8 \pm 0.3,1.5 \pm 0.3,2.1 \pm 0.8$ and $2.4 \pm 1.1 \mathrm{mmol} / \mathrm{dL})$ and $(2 \pm 0.5$, $1.7 \pm 0.4,2.5 \pm 0.5$ and $2.9 \pm 1 \mathrm{mmol} / \mathrm{dL}$ ) for studied and control groups respectively with insignificant differences between them. There was a significantly lower blood loss intraoperative and on the first day ICU, for groups IS, IIS and IIISA compared with their control groups and finally, the studied groups had significantly shorter intubation duration and ICU stay compared to their control groups, with insignificant differences in the hospital stay (Table 2).

\section{Discussion}

Needs for transfusions have been decreased in patients

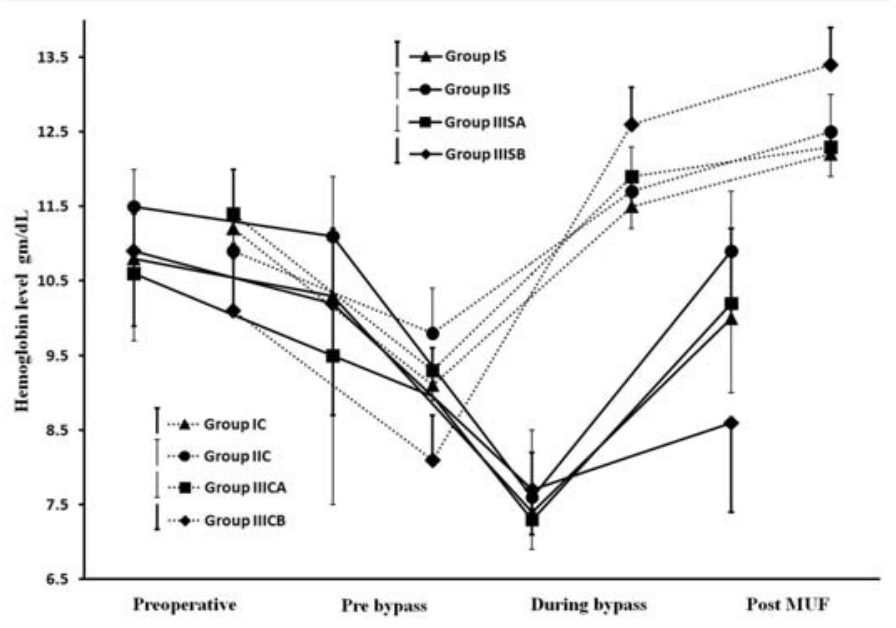

Figure 8: Hemoglobin level measurements. MUF: modified ultrafiltation.

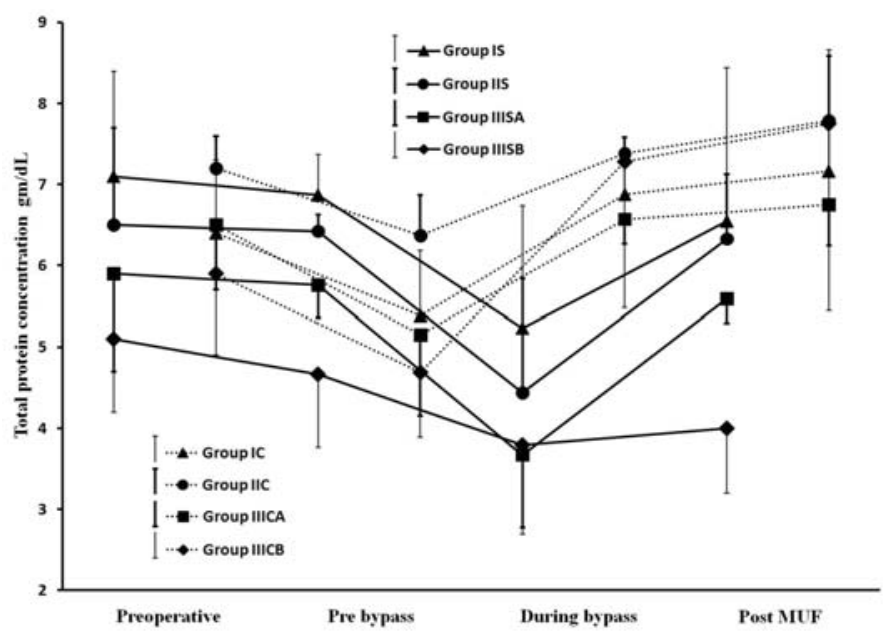

Figure 9: Total protein concentration measurements. MUF: modified ultrafiltation.

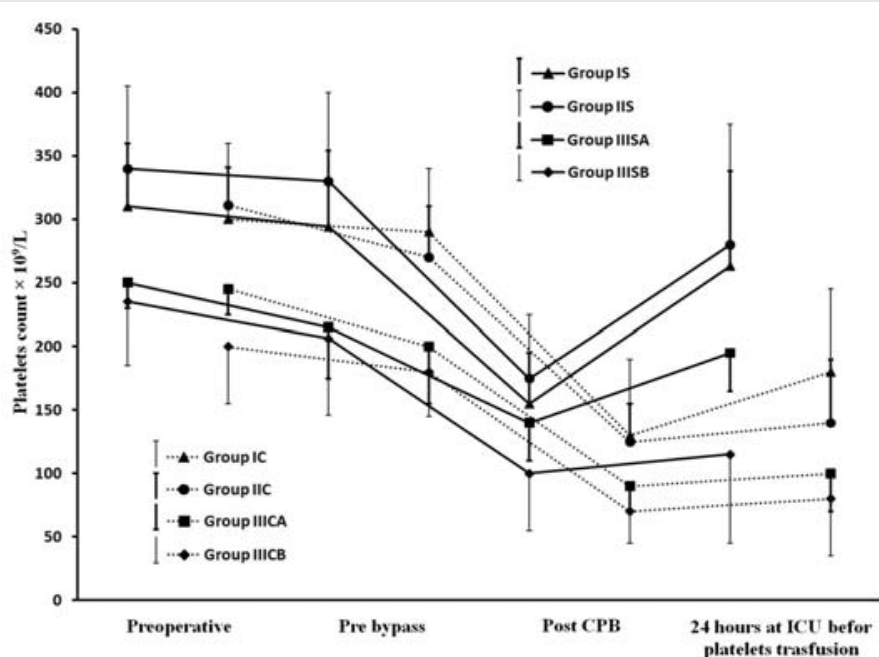

Figure 10: Platelets count measurements. ICU: intensive care unit.

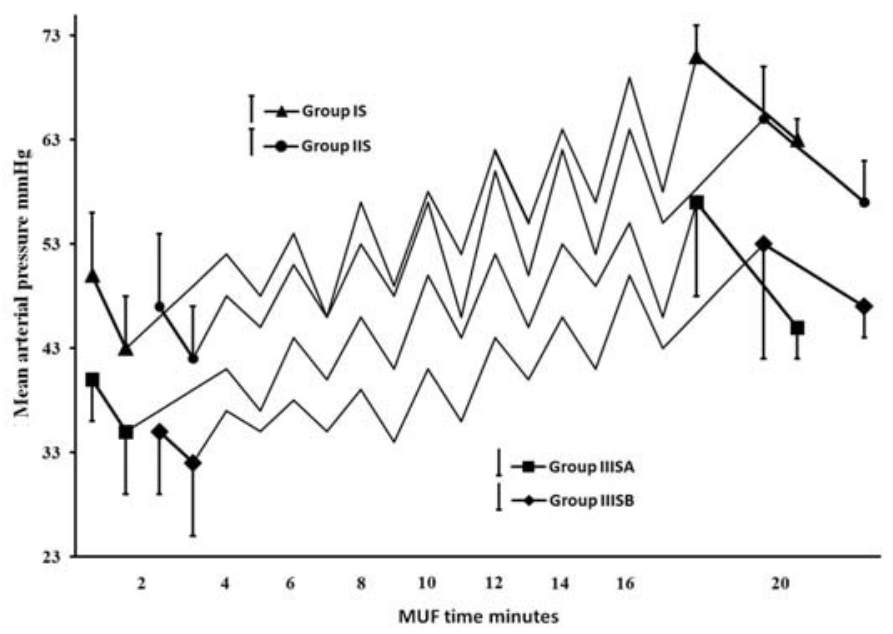

Figure 11: Systolic pressure changes during MUF. MUF: modified ultrafiltation.

undergoing open heart surgery with the development of CPB management and transfusion reduction strategies. $\mathrm{CPB}$ in pediatric cardiac surgery exposes children to severe 
hypothermia, hemodilution, and increase the blood vessels permeability because of the inflammatory reaction due to surface contact activation, which leads to unfavorable alterations such as hemodynamics changes [13-16]. Total body water increases as a result of capillary permeability which often leads to tissue edema, followed by multiple organ dysfunctions principally in lungs, heart, and brain $[17,18]$. As an alternative to hemodilution, the potential negative impacts of blood transfusion have been discussed Significantly [19], and its limited efficacy with the high costs suppress every institution board to adopt the transfusion protocol to their own local situation and its ways to reduces blood transfusion. The improvements in blood conservation protocols will further capitalize our understanding of blood conservation benefits in pediatric cardiac surgery [20].

In the field of bloodless CPB procedures; Vincent $\mathrm{F}$ and his colleagues recorded bloodless surgery in $9 \%$ of $0-6 \mathrm{~kg}$ weight group with $185 \mathrm{~mL}$ prime volume, which includes cardioplegia and ultrafilter, and so $45 \%, 58 \%$ and $78 \%$ of $6-15 \mathrm{~kg}, 15-20 \mathrm{~kg}$ and $20-40 \mathrm{~kg}$ weight groups respectively [21]. Transfusion-free CPB procedure for three cases weights $4.5,3.5$ and $3.1 \mathrm{~kg}$ with the small circuit of $200 \mathrm{~mL}$ prim volume have been reported using a dedicated pediatric heart-lung machine console with remote pump heads and intensive blood conservation efforts allowed the operation without the use of donor blood [22]. In a case report, stringent improvement of blood management strategies, particularly the downsizing of the cardiopulmonary bypass system, had enabled a transfusion-free arterial switch operation in a $1.7 \mathrm{~kg}$ prematurely born neonate [23]. Obviously, pediatric bloodless CPB procedures were remarkably accomplished using mast mounted pumps, which is unfortunately unavailable in most developing countries.

The two motives of the current study were the patient's benefits and cost reduction without extra devices, where some techniques may reduce blood transfusion of an individual patient without cost reduction. In the early development stage of such protocol as a bloodless technique for pediatric CPB procedure to overcome rare blood groups and/or a blood units unavailability, we found such technique makes our center able to perform those cases, solving perfusion side problem of hemic prime, features of low morbidity and mortality have been experienced among those pediatrics, that motivated us to represent this technique in an executable, generally treated blood conservation protocol.

The fluid management during congenital surgery should be in the midline between the two extremes poles; hemodilution pole and the blood components transfusion pole, in the matter of practical perfusion field, fluids management should be biased for one pole of them. The current blood conservation protocol biased to the hemodilution pole to the extreme level we can go and choice it as $21 \%$ Hct [24]. So we found the solution is using a limited non-hemic prime volume, and restrict the RBCs transfusion to the minimal quantities. The current protocol fulfilled using our routine roller pumps is not easily accomplished, especially when applying to neonates of $\leq 10 \mathrm{~kg}$ weights. In agreement with the importance of prime reduction [20], the routine prime of $700 \mathrm{~mL}$ has been reduced to the range of 550-350mL for the studied groups. This reduction was mainly obtained by introduction of a new setting for the $\mathrm{CPB}$ components and miniaturization of a whole $\mathrm{CPB}$ unit, with creating MFC merge the three jobs in United reduced tubes in order to minimize the effect of dead volume of MUF routine circuit, also managing the heart-lung machine position relative to the surgical table was a significant and maybe contributed to overall unit prime volume reduction more than the miniaturization of $\mathrm{CPB}$ unit itself.

These manipulations have resulted in a substantial reduction of the studied prime volumes compared to control groups, and enabling of performing 44 patients of group IIIS with non-hemic prime in an abnormal manner in dealing with these weights of non-use of blood in the CPB prime. So, each of groups IIIS and IIIC has been divided into IIIS/C A and IIIS/C B groups in the purpose of better data analysis for the impact of blood conservation protocol under discussion. Consequently, there were non-hemic prime for groups IS, IIS and IIISA, and as a result of adjusting the colloidal oncotic pressure of their entire non-hemic prime volumes, groups IS and IIISA received significantly higher protein product compared with their control groups, which adjucted just part of their prime volumes In order to facilitate the reverse process of the non-hemic prime and the significant additional ringer lactate added during CPB for groups IS, IIS and IIISA, the ultrafiltation during and after CPB was used [25-27]. For groups IIISA and IIISB in order to compensate the measurable volume of MFC to the both of body and $\mathrm{CPB}$ unit volumes and the decrease of filtration rate due to the decrease of MFC blood flow during MUF process for these small weighs group (Figure 7), hemoconcentrator TMP has been pushed to $200 \mathrm{mmHg}$ during the first $16 \mathrm{~min}$, in time of $150 \mathrm{mmHg}$ for groups IS and IIS, that enhancing the plasma water filtration rate. At the last stage of MUF, there was the problem of chasing the optimal quantity of MFC volume (which was also a measurable volume of CPB unit volume for groups IS and IIS, figure 7) contents to the patient circulation. The protocol procedure overcome this problem and enhanced the plasma filtration rate in the last $4 \mathrm{~min}$ of MUF time, by shifting up hemoconcentrator TMP to the available highest limits of 200 and $300 \mathrm{mmHg}$ for groups IS, IIS and groups IIISA, IIISB respectively, that ensure quick patient circulation evacuation for the optimal volume of MFC contents to be infused once at the end of MUF process. Hemoconcentrator TMP managements resulted in $100 \%$ efficiency of zero crystalloids achievement for all studied groups, and $100 \%$ efficiency of zero colloids achievement for groups IS, IIS, IIISA with the optimal percentage achievement for group IIISB. Also facilitate the strict chase of $\mathrm{CPB}$ unit contents to the patient's circulation, where the hemoconcentration was continuo after $100 \%$ of zero crystalloids and colloids balances achievements until the end of 20min the MUF time for all groups except group IIISB (Figure 7); during MUF process the main arterial pump flow rate makes some mixing of CPB unit residual blood with the ringer lactate added in the step of CPB unit contents chasing, so there is a rational relationship between the time of hemoconcentrator to be continuing the filtration of mixed diluted $\mathrm{CPB}$ unit contents and the increase of MFC efficiency to concentrate all CPB unit contents to the patient's circulation. In agreement with many 
studies confirming, the MUF considerably decreased the necessity for postoperative blood components transfusion $[12,28,29]$, group IIISB showed significant lower RBCs quantities as additional homologous blood components quantities in OR and the first day ICU. There was a rational relation between zero fluids balance achievement "especially colloids" and the reduction of homologous RBCs transfusion, where groups IS, IIS and IIISA did not receive any amounts of homologous blood components intraoperative and 24hours postoperative. As demonstrated in Figure 8, the current protocol shifted the $\mathrm{Hb}$ levels decrease from pre-bypass occurred in control groups to during bypass for studied groups, which was well tolerated by the hypothermia, where the main rationale for body cooling is to reduce metabolic rate sufficiently providing end-organ protection to allow greater matching between oxygen consumption and delivery [30-33], that shifting facilitated by anesthesia team members' implementation of hemodilution restriction prior to CPB as a part of conservation protocol, which was a great help in to go with the blood transfusion to the minimal transfusion trigger $(<7 \mathrm{gm} / \mathrm{dL})$ during bypass [34-38]. Then post MUF these levels showed insignificant values compared with their preoperative values except for group IIISB it didn't show such elevation, it was in the reason of incomplete MUF time to achieve the $100 \%$ colloids zero balance performance (Figure 7). The total protein concentration values showed the same pattern of hemoglobin levels as a part of blood components preserved under effect of the studied protocol (Figure 9). Platelets count recovered at 24hours postoperatively and become insignificant lower compared with their pre-bypass count values (Figure 10). By contrast to the commonly residual blood is to discarded the CPB unit residual blood or partially salvages it, because of dysfunctional platelets and subsequently impaired overall coagulation status point of view, and by agreeing to published data have shown that, most of the ill effects of CPB on platelets function and other coagulation factors are temporary and reversible within hours postoperatively [39], the conservation protocol under discussion ensures the competent preservation for patient's platelets. The large size platelets relative to the ultrafilter membrane pores were concentrated during MUF process; farther more, the high concentration of MFC blood cells decrease the mobility of all platelets sizes, and so decrease the ability to be filtrated. In a comparison of current protocol with many techniques have been used to salvage the residual blood including centrifugation/washing, direct transfusion and ultrafiltration during or post $\mathrm{CPB}$, unfortunately some of them have adverse effects, as example cell saver will only save dysfunctional RBCs, because the using of high-speed centrifugal pump affects the rheological characteristics of erythrocytes interrupting its proper oxygenation role, also its limited availability which accepted to use in $12 \mathrm{~h}$ after it was obtained, besides the cost of machine and consumables that raises the cost of regular pediatric cardiac surgery procedures. On the other hand for control groups, although the temporary effect of CPB on coagulation elements, we should avoid the temporarily destructive effect of significant high prime volumes and blood components transfusions on the inflammatory system in form of potentially trigger complement system activation pro-inflammatory cytokines, neutrophil stimulation, and endothelial cell activation [40-46]. The successful bloodless procedures performed for groups IS, IIS and IIISA pediatrics, was confirmed obviously with the significant calculated amounts of RBCs, plasma, and total protein have been autotransfused for groups IS, IIS and IIISA compared with their control groups (Table 2). Although group IIISB showed significant lesser hemic prime volume and significant reduction of homologous blood components exposure in prime, intraoperative and 24 hours postoperative compared with group IIICB, unfortunately, the protocol did not succeed to demonstrate bloodless procedure due to incomplete autotransfusion that represented in more "average 6 min" needed of MUF time in order to complete the achievement of $100 \%$ zero colloids balance (Figure 7). MUF using MFC provides more forcefully marked improvements in hemodynamic status immediately during MUF (Figure 11). In the fact of controlled hypothermic cardiac arrest may influence the trans-membrane fluid exchange resulted in an increase of myocardial interstitial fluid, many investigations have shown improvements in hemodynamics parameters after MUF including heart rate, left ventricular systolic function, systolic and diastolic blood pressure, right and left atrial pressures, pulmonary arterial pressure, cardiac function, and a reduction in myocardial wall thickness and myocardial edema $[12,47,48]$, also the correlation of improving blood pressure with the increase of blood viscosity during MUF [49]. There was a decrease in systolic pressure accompanied by continues filtration for the last 4 minutes without replacement in order to chase MFC contents into the patient circulation as a final replacement at the end of MUF process using ringer lactate solution added to the CPB unit, fortunately the former mentioned systolic pressure improvement during the first 16 minutes of MUF process makes the MFC contents chase process possible, by shifting up the systolic pressure falls into an acceptable systolic pressure range as shown in Figure 11. Consequently, the useful impact of the protocol on patient's circulation reflects the cardiovascular performance improvements resulted in significant reduction of dopamine dose for studied groups in the early postoperative period. Insignificant differences of lactate level values during operation for all groups demonstrated adequate vital organs oxygen delivery for the studied groups patients during bypass time and the successful rewarming technique used in this protocol, which include rewarming process time optimization and being shifted to the final stage of $\mathrm{CPB}$ procedure, to be ended by the end of $\mathrm{CPB}$ procedure and immediately going to MUF, that ensures reduction of normothermic oxygen demand period which is unable to be compensated by the low $\mathrm{Hg}$ level during $\mathrm{CPB}$. Using this technique, there was no effect on the spontaneous recovery of myocardium contractility at $28^{\circ} \mathrm{C}$ body temperature. May the reduction of pulmonary edema, limited blood components transfusion and the platelets count recovery of studied groups, resulted in such improvement in bleeding tendency outcome where prothrombin, factor VII, and fibrinogen levels elevated considerably by MUF which consistently been found to reduce bleeding [24], with better hemostasis clearly showed in shorter time of postoperative mechanical ventilation and ICU stay. There is an important safety feature for the usage of existing CDS such as; 1 ) Dedicated blood pumping for controlled CUF, that ensures the actual 
main arterial to be in the desired range (by adjusting arterial pump head flow compensating the MFC blood head flow during CUF), in the absence of arterial flow meter, this feature prevent or decrease the risk of an adverse neurologic outcome related to the conducting of the current blood conservation protocol during and after $\mathrm{CPB}$ procedure and perioperative time, as refered in the study demonstate the feasiblility of blood conservation methods in congenital cardiac surgery [50]. 2) Micro-bubbles trap. 3) Pressure monitoring facilitates safe management for hemoconcentrator TMP during MUF. 4) The heat exchanger prevents patient temperature drop during MUF. 5) Overcome the field bleeding continuously returns back to the venous reservoir during MUF process time by ensures the optimal colloid balance and chase all contents of CPB unit. Finally, the study results supported the successful calculations done using the mentioned formulas.

Study design and limitations: As a retrospective observational study to evaluate the consequences of the described protocol towards bloodless pediatric surgery in our institution. Unforcnitily there is no ablelity to apply a more demanding parameters like extend the MUF time of group IIISB, and there were some limitations which should be mentioned as following; 1) Although, the acceptance of perfusion team members to run their routine $\mathrm{CPB}$ procedure with fixed prime volume for control groups, there were differences in perfusion personal managements during operations that collectively could affect the variability in practices and blood components transfusion trigger point for control groups. 2) The absence of specific advanced intraoperative monitoring tools (e.g. cerebral saturation monitoring). 3) The selection of patients with healthy body weight correlated to their ages, and so normal blood volume with good hemoglobin level, in order to avoid the hemic prime as possible. 4) Big exclusion list makes the study not covering the all performed patients in these years.

\section{Conclusion}

There are sporadic successful reports of blood conservation surgery in pediatric cardiac surgery population without a concrete methodology or accepted guidelines to be adapted and implemented in the institutional practices. In most part, there are no accepted guidelines in what would be a safe Hct range during CPB in order to avoid cerebral and end-organ ischemic injuries. This observational study data demonstrated that; MFC as a basic part of the described conservation protocol was an effective and successful low-cost autotransfusion process, which facilitate the efficient and safe reverse of hemodilution and offset the dilutional coagulopathy, that enabling to conducted bloodless CPB procedures for weights $\geq 6 \mathrm{~kg}$ and minimal homologous blood components transfusion in weights $<6 \mathrm{~kg}$ using the routine CPB equipment. Since 2010 up to now, MFC has been practiced in the daily our institution practices as an ideal method to facilitate and improves fluid balances perioperatively; get the benefits of reducing or eliminating transfusion without side effects or medical troubles and being associated with lesser inotropes support and attenuation of morbidity and postoperative durations.
Research frontiers: The current study helped to expand the safety and applicability of bloodless surgery using worldwide traditional CPB circuits, components, and roller pump machines. Further studies needed to cover the additional relevant requirements for example; the adjustment of acceptable hemodilution level during $\mathrm{CPB}$, enhancement of patient preoperative Hct value, optimization of oxygen demand/supply monitoring during $\mathrm{CPB}$ and define the risk on the biophysical properties of pressurized RBCs during MUF in groups IIISA and IIISB patients.

\section{Acknowledgments}

Many thanks, to the members of Aswan university hospital. Especial thanks go to the vice president of graduate studies and research Prof. Ayman Mohammad Othman, Prof. Atef Ibrahim Saad the faculty of science dean, and Prof. Ayman Ahmad El-Amin Mohammad the head of the physics department for their interest and support for scientific studies in the field of cardiopulmonary bypass management, in order to provide the highest standard of advanced medical services providing for cardiac patients from the children of Aswan governorate. And a lot of thanks to associated prof. Hisham Hosny for his effort in reviewing the research methodology and data presentation arts.

\section{References}

1. Golab HD, Takkenberg JJ, van Gerner-Weelink GL, Marianne J. Wijers, Thierry V. Scohy, at al. (2007) Effects of cardiopulmonary bypass circuit reduction and residual volume salvage on allogeneic transfusion requirements in infants undergoing cardiac surgery. Interact Cardiovasc Thorac Surg 6: 335-339. Link: http://bit.ly/2TcuaBA

2. Bolliger D, Görlinger k, Tanaka KA (2010) Pathophysiology and Treatment of Coagulopathy in Massive Hemorrhage and Hemodilution. Anesthesiol 113 1205-1219. Link: http://bit.ly/32nSHI5

3. Tassani P, Schad H, Winkler C, Bernhard A, Ettner U, et al. (2002) Capillary leak syndrome after cardiopulmonary bypass in elective, uncomplicated coronary artery bypass grafting operations: Does it exist? J Thorac Cardiovasc Surg 123: 735-741. Link: http://bit.ly/2v15jJ

4. Dongaonkar RM, Stewart RH, Geissler HJ, Laine GA (2010) Myocardial microvascular permeability, interstitial oedema, and compromised cardiac function. Cardiovasc Res 87: 331-339. Link: http://bit.ly/2up0VTT

5. Yaroustovsky M, Abramyan M, Komardina E, Nazarova H (2017) Blood purification in intensive care patients with multiple organ dysfunction syndrome and sepsis after cardiac surgery. Vessel Plus 1: 49-60. Link: http://bit.ly/3c2AXGY

6. Alves Rodrigues CD, de Oliveira RARA, PizaSoares SM, De Figueiredo LC, Araújo, Dragosavac D (2010) Lung injury and mechanical ventilation in cardiac surgery: A review. Rev Bras Terlntensiva 22: 375-383. Link: http://bit.ly/2HPqn8f

7. Bhaskar B, Dulhunty J, Mullany DV, Fraser JF (2012) Impact of Blood Produc Transfusion on Short and Long-Term Survival After Cardiac Surgery: More Evidence. Ann Thorac Surg 94: 460-467. Link: http://bit.ly/2unLE5K

8. Murphy GJ, Reeves BC, Rogers CA, Rizvi S, Culliford L, et al. (2007) Increased Mortality, Postoperative Morbidity, and Cost After Red Blood Cell Transfusion in Patients Having Cardiac Surgery. Circulation 116: 2544-2552. Link: http://bit.ly/37NZL1W

9. Boettcher W, Merkle F, Koster A (2003) Safe minimization of cardiopulmonary bypass circuit volume for complex cardiac surgery in a $3.7 \mathrm{~kg}$ neonate Perfusion 18: 377-379. Link: http://bit.ly/32rG1jB 
10. Kwak JG, Park M, Lee J, Lee CH (2016) Multiple Approaches to Minimize Transfusions for Pediatric Patients in Open-Heart Surgery. Pediatr Cardiol 37 44-49. Link: http://bit.ly/2SVCUgS

11. Karamlou T, Ungerleider RM (2014) Systemic inflammatory response to cardiopulmonary bypass in pediatric patients and related strategies for prevention. In Pediatric and Congenital Cardiology, Cardiac Surgery and Intensive Care. Springer-Verlag London Ltd. 791-800. Link: http://bit.ly/3c592py

12. Ziyaeifard M, Alizadehasl A, Massoumi G (2014) Modified Ultrafiltration During Cardiopulmonary Bypass and Postoperative Course of Pediatric Cardiac Surgery. Res Cardiovasc Med 3: e17830. Link: http://bit.ly/2unMol4

13. Miyaji K, Kohira S, Miyamoto T (2007) Pediatric cardiac surgery without homologous blood transfusion, using a miniaturized bypass system in infants with lower body weight. J ThorcCardiovasc Surg 134: 284-289. Link: http://bit.ly/2vamlEl

14. Zeybek R, Adanir T, Iskesen I, TÜZÜN E (2001) The Hemodynamic Responses to Hypothermic and Normothermic Cardiopulmonary Bypass. Turk J Med Sci 31: 429-443. Link: http://bit.ly/3bWNr2N

15. Lee JM, Byon HJ, Kim JT, Kim HS, Kim CS (2010) Transfusion-free anesthetic management for open heart surgery in a neonate -A case report. Korean $J$ Anesthesiol 59: S141-S145. Link: http://bit.ly/2HOh8oX

16. Itoh $\mathrm{H}$, Ichiba $\mathrm{S}$, Ujike $\mathrm{Y}$ (2016) A prospective randomized trial comparing the clinical effectiveness and biocompatibility of heparin-coated circuits and PMEA-coated circuits in pediatric ardiopulmonary bypass. Perfusion 31: 247254. Link: http://bit.ly/38VQqX4

17. Feng G, Luo Q, Guo E, Yao Y, Yang F, et al. (2015) Multiple organ dysfunction syndrome, an unusual complication of heroin intoxication: a case report and review of literature. Int J Clin Exp Pathol 8: 11826-11830. Link: http://bit.ly/3a3kG2F

18. Spapen HD, Jacobs R, Honoré PM (2017) Sepsis-induced multi-organ dysfunction syndrome-a mechanistic approach. J EmergCrit Care Med 1: 27. Link: http://bit.ly/2SQrLOB

19. Marcucci C, Madjdpour C, Spahn DR (2004) Allogeneic blood transfusions: benefit, risks and clinical indications in countries with a low or high human development index. British Medical Bulletin 70: 15-28. Link: http://bit.ly/2PgXB4E

20. Mirinazhad M, Azarfarin R, Bilehjani E, Vahedpour A (2009) The Effect of Acute NormovlumicHemodilution in Reducing Allogenic Red Blood Cell Transfusion During and After Cardiac Surgery. CardiovascThorac Res 1: 35-42. Link: http://bit.ly/2SSozBv

21. Olshove VF, Preston T, Gomez D, Phillips A, Galantowicz M (2010) Perfusion Techniques Toward Bloodless Pediatric Open Heart Surgery. J Extra Corpor Technol 42: 122-127. Link: http://bit.ly/2PkWmBh

22. Boettcher W, Merkle F, Huebler M, Koster A, Schulz F, et al. (2005) TransfusionFree Cardiopulmonary Bypass in Jehovah's Witness Patients Weighing Less Than 5 kg. J Extra Corpor Technol 37: 282-285. Link: http://bit.ly/2T7F1wY

23. Huebler M, Redlin M, Boettcher W (2008) Transfusion-free arterial switch operation in a $1.7-\mathrm{kg}$ premature neonate using a new miniature cardiopulmonary bypass system. J Card Surg 23: 358-360. Link: http://bit.ly/37QkIJt

24. Habib RH, Zacharias A, Schwann TA, Riordan CJ, Durham SJ et al. (2003) Adverse effects of low hematocrit during cardiopulmonary bypass in the adult: Should current practice be changed? J Thorac Cardiovasc Surg 125: 14381450. Link: http://bit.ly/2TmLNiz

25. Thapmongkol S, Masaratana P, Subtaweesin T, Sayasathid J, Thatsakorn $\mathrm{K}$, et al. (2015) The effects of modified ultrafiltration on clinical outcomes of adult and pediatric cardiac surgery. Asian Biomedicine 9: 591-599. Link: http://bit.ly/2unNuUc
26. Neal JR, Blau CL, Cornelius AM, Pike RB, Dearani JA, et al. (2016) Nove Applications of Modified Ultrafiltration and Autologous Priming Techniques to Reduce Blood Product Exposure on ECMO. J Extra Corpor Technol 48: 23-26. Link: http://bit.ly/32rHDKb

27. Wang S, Palanzo D, Ündar A (2012) Current ultrafiltration techniques before during and after pediatric cardiopulmonary bypass procedures. Perfusion 27 438-446. Link: http://bit.ly/2HRFg9X

28. Torina AG, Silveira-Filho LM, Vilarinho KAS, Eghtesady P, Oliveira PPM et al. (2012) Use of modified ultrafiltration in adults undergoing coronary artery bypass grafting is associated with inflammatory modulation and less postoperative blood loss: A randomized and controlled study. J Thorac Cardiovasc Surg 144: 663-670. Link: Link: http://bit.ly/3c1CAVh

29. Ootaki Y, Yamaguchi M, Oshima Y, Yoshimura N, Oka S (2002) Effects of Modified Ultrafiltration on Coagulation Factors in Pediatric Cardiac Surgery Surg Today 32: 203-206. Link: http://bit.ly/2ViMFHA

30. Mongardon N, Kohlhauer M, Lidouren F, Hauet T, Giraud S, et al. (2016) A Brief Period of Hypothermia Induced by Total Liquid Ventilation Decreases End-Organ Damage and Multiorgan Failure Induced by Aortic Cross-Clamping Anesth Analg 123: 659-669. Link: Link: http://bit.ly/395NQhe

31. Salazar J, Coleman R, Griffith S, McNeil J, Young H, et al. (2009) Brain preservation with selective cerebral perfusion for operations requiring circulatory arrest: protection at $25^{\circ} \mathrm{C}$ is similar to $18^{\circ} \mathrm{C}$ with shorter operating times. Eur J Cardio-thoracic Surg 36: 524-531. Link: http://bit.ly/2VeP8T4

32. Englum BR, Andersen ND, Husain AM, Mathew JP, Hughes GC (2013) Degree of hypothermia in aortic arch surgery - optimal temperature for cerebral and spinal protection: deep hypothermia remains the gold standard in the absence of randomized data. Ann Cardiothorac Surg 2: 184-193. Link: http://bit.ly/2SRJBjK

33. Fehrenbacher JW, Hart DW, Huddleston E, Siderys H, Rice C (2007) Optima End-Organ Protection for Thoracic and Thoracoabdominal Aortic Aneurysm Repair Using Deep Hypothermic Circulatory Arrest. Ann ThoracSurg 83: 1041 1046. Link: http://bit.ly/3aaidnd

34. Kotani Y, Honjo O, Nakakura M, Fujii Y, Ugaki S, et al. (2009) Single Cente Experience With a Low Volume Priming Cardiopulmonary Bypass Circuit for Preventing Blood Transfusion in Infants and Small Children. ASAIO 55: 296 299. Link: http://bit.ly/2HRsSXK

35. Carson JL, Stanworth SJ, Roubinian N, Fergusson DA, Triulzi D, et al. (2016) Transfusion thresholds and other strategies for guiding allogeneic red blood cell transfusion. Cochrane Database of Syst Rev 10: Art. No: CD002042. Link: http://bit.ly/38Pxauq

36. Rahimi-Levene N, Ziv-Baran T, Peer V, Kornberg A, Zeidenstein R, et al (2018) Hemoglobin transfusion trigger in an internal medicine department - A "real world" six year experience. PLoS ONE 13: e0193873. Link: http://bit.ly/38ThVRn

37. Salpeter SR, Buckley JS, Chatterjee S (2014) Impact of More Restrictive Blood Transfusion Strategies on Clinical Outcomes: A Meta-analysis and Systematic Review. Am J Med 127: 124-131. Link: http://bit.ly/2TfUs6m

38. Carson JL, Hebert PC (2014) Should We Universally Adopt a Restrictive Approach to Blood Transfusion? It's All About the Number. Am J Med 127 103-104. Link: http://bit.ly/2vZ5V1Y

39. Colli A, Balduzzi S, Ruyra X (2012) The Hemobag: The modern ultrafiltration system for patients undergoing cardiopulmonary bypass. J Cardiothoracic Surg 7: 55-60. Link: http://bit.ly/2vWifjA

40. Rossaint J, Berger C, Aken HV, Scheld HH, Zahn PK, et al. (2012) Cardiopulmonary Bypass during Cardiac Surgery Modulates Systemic Inflammation by Affecting Different Steps of the Leukocyte Recruitment Cascade. PLoS ONE 7: e45738. Link: http://bit.ly/2VgRReY 
41. Mócsai A, Walzog Ba, Lowell CA (2015) Intracellular signalling during neutrophil recruitment. Cardiovasc Res 107: 373-385. Link: http://bit.ly/2SStGBJ

42. Basiglio CL, Arriaga SM, Pelusa F, Almará AM, Kapitulnik J, et al. (2010) Complement activation and disease: Protective effects of hyperbilirubinaemia. Clinical Science 118: 99-113. Link: http://bit.ly/39SZex4

43. Denk S, Neher MD, Messerer DAC, Wiegner R, Nilsson B, at al. (2017) Complement $\mathrm{C} 5 \mathrm{a}$ Functions as a Master Switch for the $\mathrm{pH}$ Balance in Neutrophils Exerting Fundamental Immunometabolic Effects. J Immunol 198 4846-4854. Link: http://bit.ly/2Vckmue

44. Döhrmann S, Cole JN, Nizet V (2016) Conquering Neutrophils. PloS Pathog 12 e1005682. Link: http://bit.ly/2HS4tkS

45. Ricklin D, Hajishengallis G, Yang K, Lambris JD (2010) Complement - a key system for immune surveillance and homeostasis. Nat Immunol 11: 785-797. Link: http://bit.ly/3c2RASH

46. Ekdahl KN, Lambris JD, Elwing H, Ricklin D, Nilsson PH, et al. (2011) Innate immunity activation on biomaterial surfaces: A mechanistic model and coping strategies. Adv Drug Deliv Rev 63: 1042-1050. Link: http://bit.ly/2vapDry

47. Kazuto $Y$, Shin T, Takuya $\mathrm{K}$ (2009) Removal of prostaglandin $\mathrm{E}_{2}$ and increased intraoperative blood pressure during modified ultrafiltration in pediatric cardiac surgery. J Thorac Cardiovasc Surg 137: 730-735. Link: http://bit.ly/38UlipY

48. Zhou G, Feng Z, Xiong H, Duan W, Jin Z (2013) A combined ultrafiltration strategy during pediatric cardiac surgery: a prospective, randomized controlled study with clinical outcomes. J Cardiothorac Vasc Anesth 27: 897 902. Link: http://bit.ly/32lpc9W

49. Çinar Y, Şenyol AM, Duman K (2001) Blood Viscosity and Blood Pressure: Role of Temperature and Hyperglycemia. AJH 14: 433-438. Link: http://bit.ly/2vdNpCS

50. Karimi M, Sullivan JM, Linthicum C, Mathew A (2017) Blood conservation pediatric cardiac surgery in all ages and complexity levels. World $\mathrm{J}$ Cardiol 9 : 332-338. Link: http://bit.ly/3c003Es

\section{Discover a bigger Impact and Visibility of your article publication with} Peertechz Publications

\section{Highlights}

* Signatory publisher of ORCID

* Signatory Publisher of DORA (San Francisco Declaration on Research Assessment)

* Articles archived in worlds' renowned service providers such as Portico, CNKI, AGRIS, TDNet, Base (Bielefeld University Library), CrossRef, Scilit, J-Gate etc.

* Journals indexed in ICMJE, SHERPA/ROMEO, Google Scholar etc.

* OAI-PMH (Open Archives Initiative Protocol for Metadata Harvesting)

* Dedicated Editorial Board for every journal

- Accurate and rapid peer-review process

* Increased citations of published articles through promotions

* Reduced timeline for article publication

Submit your articles and experience a new surge in publication services (https://www.peertechz.com/submission).

Peertechz journals wishes everlasting success in your every endeavours.

Copyright: (C) 2020 Saleh M. This is an open-access article distributed under the terms of the Creative Commons Attribution License, which permits unrestricted use distribution, and reproduction in any medium, provided the original author and source are credited. 